\title{
DIREITO-DEVER FUNDAMENTAL E HUMANO DO AMBIENTE E O BLOCO DE CONSTITUCIONALIDADE BRASILEIRO
}

Leonardo Furian ${ }^{1}$

\section{Resumo:}

O presente artigo versa sobre o bloco de constitucionalidade brasileiro e os tratados de direito do ambiente, sob a perspectiva da Constituição brasileira de 1988 que possui cláusula de abertura do catálogo dos direitos fundamentais. A questão proposta é se as Convenções de direito ambiental ingressam no ordenamento jurídico nacional em que hierarquia: legal, constitucional ou supralegal. Discute-se com os argumentos da doutrina, que se debruça sobre a temática mais ampla dos tratados de direitos humanos desde o Congresso Constituinte e resume-se a evolução jurisprudencial do STF até os julgados mais recentes. A pesquisa é bibliográfica e a metodologia analítica.

Palavras-chaves: Direito-dever do ambiente; bloco de constitucionalidade; Tratados de direito do ambiente.

\section{FUNDAMENTAL AND HUMAN RIGHT-DUTY OF THE ENVIRONMENT AND THE BRAZILIAN CONSTITUTIONAL BLOC}

\begin{abstract}
:
This article deals with the Brazilian constitutionality bloc and the environmental law treaties, from the perspective of the 1988 Brazilian Constitution, which has a clause to open the catalog of fundamental rights. The proposed question is whether the Conventions of environmental law enter the national legal order in which hierarchy: legal, constitutional or superior to law. It is discussed with the doctrine's arguments, which deals with the broader thematic of human rights treaties since the Constituent Congress and summarizes the jurisprudential evolution of the STF until the most recent judgments. The research is bibliographic and the methodology is analytical.
\end{abstract}

Keywords: Right-duty of the environment; constitutionality bloc; Environmental law treaties.

\section{Introdução}

A relação entre o direito interno e o direito internacional é um tema clássico do desenvolvimento da teoria jurídica e das relações entre as nações que nos últimos tempos e, especialmente após a guerra fria, cresceu em importância em razão da multiplicação dos tratados internacionais multilaterais, do advento de Tribunais Internacionais e da progressiva

\footnotetext{
${ }^{1}$ Aluno do Mestrado em Direito no PPGD - Mestrado e Doutorado/URI, Campus Santo Ângelo-RS. Procurador Federal da Advocacia-Geral da União - AGU, especialista em Direito Público pela Universidade Nacional de Brasília - UNB, Bacharel em Ciências Jurídicas e Sociais pela Pontifícia Universidade Católica do Rio Grande do Sul - PUC/RS.
} 
evolução dos sistemas de proteção de direitos humanos, seja em âmbito regional, seja em âmbito onusiano.

No específico caso do direito do ambiente essa relação foi - e tem sido - muito profícua para o Brasil desde o advento da Constituição brasileira de 1988, e diversos temas e disciplinas legais fundamentam-se direta ou indiretamente em tratados que vieram a ser internalizados. De outra banda as implicações a respeito da vinculação e efetividade dos tratados do direito do ambiente estão inseridas noutro assunto que, do mesmo modo, tem angariado novos contornos em razão da contribuição doutrinária e da jurisprudência do Supremo Tribunal Federal - STF entorno do bloco de constitucionalidade da Constituição brasileira de 1988, sua extensão, sua hierarquia e a possibilidade de abertura material do catálogo de direitos fundamentais pelo artigo $5^{\circ}, \S 2^{\circ}$.

Se por um lado essa relação do direito internacional do ambiente com o ordenamento jurídico brasileiro é salutar em termos de um desenvolvimento sustentável ao encontro das diretrizes constitucionais ao estabelecer níveis protetivos da natureza mais elevados; de outro lado acarreta problemas de aplicação interna no que diz com quais normas incidem no caso concreto ou na matéria regulada e qual a posição hierárquica do ordenamento jurídico ocupam.

Assim, questiona-se se os tratados de direito do ambiente ingressam no bloco de constitucionalidade da Constituição brasileira de 1988 e qual sua posição hierárquica no ordenamento nacional. Antes do desenvolvimento do tema, necessário pontuar o entendimento quanto a fundamentalidade e a expressão direito-dever fundamental e humano do ambiente, ora utilizada.

A pesquisa é bibliográfica e a metodologia analítica.

\section{Entendimentos adotados}

Antes de ingressar no ponto de análise, sublinha-se a diferenciação com significação e fundamentação diversa entre direito humano, que remete à disciplina por documento internacional, ao passo que, ao utilizar-se do termo direitos fundamentais, a referência é quanto ao texto da Constituição e, ademais, ao uni-los em direitos fundamentais e humanos, a regência é ampliada às duas ordens jurídicas.

Com isso, está a evitar-se uma equivocidade ainda maior, própria do termo direitos humanos e suas amplas definições e possibilidades, conforme Antonio Enrique Pérez Luño 
(2018, p. 24-25). A Constituição brasileira de 1988 não só não contribui nessa definição como corrobora para falta de precisão ao estabelecer termos dos mais diversos. Conforme notícia André de Carvalho Ramos (2016, p. 42-43), nos instrumentos internacionais igualmente há uma infinidade de termos. Em doutrina as posições, em apertadíssima síntese, são de três ordens: quem defenda que não há razão de ser a diferenciação, como André de Carvalho Ramos; quem une os dois termos em "direitos humanos fundamentais", como Alexandre de Moraes (2013); e quem vê diferenças como José Joaquim Gomes Canotilho (2003, p. 393), Antonio Enrique Peréz Luño (2018, p. 33); Fábio Konder Comparato (2017, p. 239) e Ingo Wolfgang Sarlet (2018, p. 35).

Ademais, parte-se do entendimento de que o direito do ambiente, além de direito fundamental, é humano. Quanto ao conceito de direito humano, não restam maiores desafios argumentativos, na medida em que basta sua previsão em enunciado de documento internacional, sendo que sua fundamentação, para a Corte Interamericana de Direitos Humanos - CIDH, está além da interdependência dos demais direitos e ao ambiente saudável, ele próprio é um direito autônomo digno de respeito e de proteção (CIDH, OC-23, 2017, p. 25). Na perspectiva nacional, quanto ao direito ao ambiente, há certo consenso quanto à sua fundamentalidade (KRELL, 2013, p. 2078). ${ }^{2}$ Além da doutrina posicionar-se favoravelmente ao direito fundamental ao ambiente, o STF, em seus julgados, também, vem considerando esse entendimento. ${ }^{3}$

Mesmo não estando diretamente previsto pelo catálogo de direitos fundamentais, embora conste como um dos objetos da ação popular pela qual qualquer cidadão possa anular ato lesivo ao ambiente (artigo 5º , LXXIII, da Constituição brasileira de 1988), está formalmente expresso pelo artigo 225, além de ter a dimensão material pela relação com o regime democrático e os princípios adotados. Há uma estreita conexão do ambiente com o princípio da dignidade da pessoa humana (artigo $1^{\circ}$, III, da Constituição brasileira de 1988), a solidariedade e o desenvolvimento como objetivo da República, além dos direitos

\footnotetext{
${ }^{2}$ A CIDH cita que os seguintes Estados das Américas consagram o direito ao ambiente em suas Constituições, além do Brasil: Argentina, Bolívia, Chile, Colômbia, Costa Rica, Equador, El Salvador, Guatemala, México, Nicarágua, Panamá, Paraguai, Peru, Dominicana, Venezuela (CIDH, OC-23, 2017, p. 26-27).

${ }^{3}$ Como exemplo, dois julgados recentes: "As medidas provisórias não podem veicular norma que altere espaços territoriais especialmente protegidos, sob pena de ofensa ao art. 225, inciso III, da Constituição da República. As alterações promovidas pela Lei n. ${ }^{\circ}$ 12.678/2012 importaram diminuição da proteção dos ecossistemas abrangidos pelas unidades de conservação por ela atingidas, acarretando ofensa ao princípio da proibição de retrocesso socioambiental, pois atingiram o núcleo essencial do direito fundamental ao meio ambiente ecologicamente equilibrado previsto no art. 225 da Constituição da República" (STF, ADI 4.717, 2019). E a ação que abaixo será analisada a respeito da inconstitucionalidade do Amianto (STF, ADI, 4.066, 2018).
} 
fundamentais expressos como o direito à vida, que o ambiente é salutar e essencial em sua qualidade.

Ainda no que diz com a expressão direito-dever utiliza-se por acolher a ampla dimensionalidade da realidade social e normativa ao trazer consigo a noção daquilo que Casalta Nabais denominou de direito bumerangue, ao passo que estabelece aspectos de direitos subjetivos de uma banda; de outra banda demanda condutas dos titulares com vistas a proteger o bem ambiental com igual posição constitucional na forma de dever fundamental (NABAIS, 2009, p. 53).

\section{Direito-dever fundamental e humano do ambiente e o bloco de constitucionalidade}

Expostos os entendimentos adotados necessários para o andamento do trabalho, o que se desenvolve é referente à posição constitucional e como se dá o diálogo com o direito internacional, isto é, como o "direito interno vê o direito internacional" (RAMOS, 2016, p. 304) no que se refere ao direito-dever do ambiente.

Recentemente, o STF, em julgamento referente ao amianto em alguns votos em obter dictum, foi mencionado o tema da hierarquia das normas de direito do ambiente dos tratados internalizados. Antes de comentar o referido julgamento, necessário faz-se uma exposição, resumidamente, sobre a interpretação doutrinária e jurisprudencial da abertura material do catálogo de direitos fundamentais.

Para uma noção introdutória, entende-se por bloco de constitucionalidade os enunciados de textos com a mesma hierarquia da Constituição, mesmo sem estar presente em seu documento principal. A concepção e a formulação da teoria do bloco de constitucionalidade originam-se do Direito francês, que formou um sistema de controle de constitucionalidade das leis com especificidades diversas do restante dos países europeus. Como a atual Constituição francesa de 1958 não tem previsto um catálogo ou declaração de direitos e liberdade, atendo-se à previsão da organização do Estado e do sistema e regime de governo, entre 1970-1973, "o Conselho Constitucional realizou uma verdadeira revolução, reconhecendo força jurídica ao Preâmbulo da Constituição" (FAVOREOU, 2004, p. 97-98, grifo no original), que fazia referência à Declaração dos Direitos do Homem e do Cidadão da Revolução Francesa e ao preâmbulo da Constituição de 1946. Assim, compõe o bloco de constitucionalidade, além da própria Constituição em vigor, a Declaração dos revolucionários de 1789, o preâmbulo da Constituição de 1946 (que se refere aos princípios fundamentais 
pelas leis da República além de diversos direitos), os princípios fundamentais reconhecidos pelas leis da República. Além desses, desde 2003, compõe o bloco de constitucionalidade francês a Carta ao Meio Ambiente.

No Brasil, desde a promulgação da Constituição de 1988, tem-se debatido o tema e considera-se pertencente ao bloco de constitucionalidade, de um modo geral: texto da Constituição, Atos de Disposição Constitucional Transitória, texto de Emendas à Constituição que não integram a parte principal; direitos implícitos ou não escritos e os tratados incorporados no direito nacional pelo rito do artigo $5^{\circ}, \S 3^{\circ}$ (acrescido pela Emenda à Constituição n. 45 de 2004), o que foi executado na internalização da Convenção sobre o Direito das Pessoas com Deficiência e seu Protocolo Facultativo, até o presente os dois tratados que seguiram o rito (SARMENTO, 2018, p. 62).

Não obstante subsistam questões a serem aplanadas pelas consequências do $\S 3^{\circ}$ do artigo $5^{\circ}$, uma vez que somente dois instrumentos foram incorporados pela "nova" regra de procedimento, a problemática quanto à hierarquia resta sanada pelo rito similar ao de reforma constitucional para os instrumentos que forem submetidos. A polêmica persistente, se integram ou não o bloco de constitucionalidade brasileiro, dá-se com relação ao $§ 2^{\circ}$ do artigo $5^{\circ}$, que traz a abertura material do catálogo de direitos fundamentais, e se abriga sob seu guarda-chuva protetivo os tratados de direitos humanos incorporados nos termos dos artigos 84, VIII e 49, I, todos da Constituição brasileira de 1988, que consagraram a teoria da junção de vontades ou dos atos complexos ${ }^{4}$, e dispõem, respectivamente, sobre a atribuição do Presidente da República em celebrar tratados, e, ao Congresso Nacional, resolver definitivamente sobre os mesmos, o que é feito mediante aprovação de Decreto Legislativo ${ }^{5}$,

${ }^{4}$ Conforme André de Carvalho Ramos (2016, p. 308) é necessária, para celebração de um tratado, a "conjunção de vontades do Poder Executivo e do Poder Legislativo", o que se designa na teoria da junção de vontades. O trâmite dá-se após as negociações na seara internacional e assinatura, pelo Presidente da República, do Tratado, sendo, então, encaminhada uma mensagem ao Congresso Nacional, que poderá aprovar o texto por meio de Decreto Legislativo e autorizar a chefia do Poder Executivo a celebrar o tratado, que poderá ou não o fazer. Celebrado o tratado entra em vigor para o direito internacional, mas somente ingressará no sistema jurídico brasileiro com o Decreto de Promulgação ou Decreto Presidencial com o referendo do Ministro das Relações Exteriores, nos termos do artigo 87, I, da Constituição brasileira de 1988 (RAMOS, 2016, p. 309).

${ }^{5}$ A temática remonta à doutrina acerca da relação entre Direito interno e internacional designada de dualismo e monismo. O dualismo preconiza que há duas ordens jurídicas independentes e que não se relacionam, ao passo que o monismo estabelece que "o direito constitui uma unidade, um sistema, e que tanto o direito internacional quanto o direito interno integram esse sistema" (BARROSO, 2009, p. 16). Sem disposição constitucional que regule o diálogo entre Constituição e tratados internacionais, a evolução jurisprudencial e boa parte da doutrina são da opinião que o direito brasileiro se alinha a um monismo moderado (BARROSO, 2009, p. 19). Nadia de Araújo e Inês da Matta Andreiuolo (1999, p. 109-110), em artigo anterior à inclusão do $\S 3^{\circ}$, do artigo $5^{\circ}$, da Constituição brasileira de 1988, embora entendam que a hierarquia dos tratados de direitos humanos seja do mesmo nível da Constituição, lecionam que o Brasil é um país dualista, em razão de que há um procedimento 
ou seja, sem observância da regra procedimental de dois turnos em cada Casa Legislativa e a maioria exigida no $\$ 3^{\circ}$ do artigo $5^{\circ}$. André de Carvalho Ramos (2016, p. 328), inclusive, divide em bloco de constitucionalidade amplo, o entendimento que abrange os tratados de direitos humanos independente da forma de internalização; bloco de constitucionalidade restrito, em que não são inclusos os tratados de direitos humanos que não observaram a regra de procedimento similar à reforma constitucional. Além do período anterior à previsão da internalização dos tratados de direitos humanos pelo rito similar das Emendas à Constituição, com os tratados que entraram em vigor até então e se há possibilidade de recepção, persiste o interesse e a polêmica em razão de que a utilização do rito mais dificultoso não é obrigatória pelo Parlamento brasileiro, pois, mesmo após a reforma constitucional, pode-se utilizar do procedimento do Decreto Legislativo com a promulgação por Decreto Presidencial, ao menos, é essa posição que tem prevalecido.

A história da teoria constitucional e da jurisprudência que se formou com a atual Constituição tem como marca uma crescente valorização dos direitos humanos na sua dimensão de direito material e processual (com a orientação para que o Brasil propugne a criação de um Tribunal Internacional dos Direitos Humanos, desde a redação original no artigo $7^{\circ}$ no Ato das Disposições Constitucionais Transitórias (ADCT), e com a inclusão do $\S 4^{\circ}$ do artigo $5^{\circ}$, pela Emenda à Constituição de n. ${ }^{\circ} 45$, da submissão à jurisdição do Tribunal Penal Internacional).

A sugestão e a redação da abertura material do catálogo dos direitos fundamentais, conforme relatam Celso Albuquerque Mello (2001, p. 2), Daniel Sarmento (2018, p. 62) e o próprio formulador, foi feita por Antonio Augusto Cançado Trindade (2003, p. 512) que, ao tempo da constituinte, era consultor jurídico do Ministério das Relações Exteriores. Seguiuse, independentemente da paternidade, uma tradição da evolução constitucional brasileira, conforme bem relata Ingo Wolfgang Sarlet (2018, p. 79), que remonta à primeira Constituição republicana de 1891, não obstante as variações textuais, mas com ratio similares. O propósito dessa formulação, ou, para utilizar uma expressão, há muito, ultrapassada, a vontade do legislador, foi, realmente, de equiparar na mesma hierarquia constitucional os tratados ou as convenções de direitos humanos que o Brasil viesse a ser parte contratante.

para internalização dos tratados que, quando feito, passa a ser norma vigente no ordenamento nacional e de Direito interno, portanto. Por sua vez, para Antonio Augusto Cançado Trindade (2003, p. 506), o "direito internacional e o direito interno aqui se mostram, desse modo, em constante interação, em benefício dos seres humanos protegidos". 
Para o internacionalista brasileiro, o $\S 2^{\circ}$ do artigo $5^{\circ}$ da Constituição brasileira de 1988:

\begin{abstract}
"[...] se insere na nova tendência de Constituições latino-americanas recentes de conceder um tratamento especial ou diferenciado também no plano do direito interno aos direitos e garantias individuais internacionalmente consagrados. A especificidade e o caráter especial dos tratados de proteção internacional dos direitos humanos encontram-se, com efeito, reconhecidos e sancionados pela Constituição Brasileira de 1988: se, para os tratados internacionais em geral, se tem exigido a intermediação pelo poder Legislativo de ato com força de lei de modo a outorgar a suas disposições vigência ou obrigatoriedade no plano do ordenamento jurídico interno, distintamente no caso dos tratados de proteção internacional dos direitos humanos em que o Brasil é Parte os direitos fundamentais neles garantidos passam, consoante os artigos 5(2) e 5(1) da Constituição Brasileira de 1988, a integrar o elenco dos direitos constitucionalmente consagrados e direta e imediatamente exigíveis no plano do ordenamento jurídico interno.” (TRINDADE, 2003, p. 513).
\end{abstract}

Antonio Augusto Cançado Trindade ${ }^{6}$, desse modo, preconizava, além da hierarquia constitucional, a aplicabilidade imediata dos tratados de proteção aos direitos humanos, sem necessidade de interferência legislativa, em razão de uma interpretação teleológica e sistemática dos dispositivos constitucionais. Entretanto nenhum dos dois entendimentos foi seguido pelo STF.

A interpretação inicial dada pelo STF, referente à invocação da abertura material do catálogo de direitos fundamentais pela Constituição brasileira de 1988 e a hierarquia dos tratados de direitos humanos, seguiu a lógica de então: interpretar o novo com os olhos do velho, ou seja, continuou a aplicar o entendimento anterior sob a Constituição de 1967/69 como se nada tivesse ocorrido com a entrada em vigor, no mundo jurídico, de um novo fundamento de validade.

Para Lenio Streck (2002, p. 37), "o advento do novo fundamento de validade não chegou a criar a necessária empolgação no seio dos operadores do direito" (grifo no original). O STF, diante do novo fundamento de validade do Direito brasileiro foi excessivamente autocontido e sem atentar para os novos institutos e o novo texto que visava inaugurar um sentimento constitucional. Nesse sentido, além da objeção à jurisprudência tímida quanto à abertura material do catálogo de direitos fundamentais, o entendimento sobre alguns temas de jurisdição constitucional também é representativo desse período dos anos noventa do século passado, como o caso ou descaso com os instrumentos para colmatar a

\footnotetext{
${ }^{6}$ Ainda que o tratado citado do internacionalista seja de 1997, com a segunda edição citada de 2003, ou seja, em momento que o STF já havia se manifestado de forma diversa à proposta, o autor cita que seu entendimento remete ao momento da constituinte, como antes referido (TRINDADE, 2003, p. 512).
} 
omissão do legislador (ação direita de inconstitucionalidade por omissão e mandado de injunção, em que se contentava com um ofício comunicando a omissão julgada); a adoção da tese que diferenciou inconstitucionalidade e não recepção e, com isso, escusando-se de examinar a constitucionalidade das leis promulgadas sob a Constituição de 1967/69, uma vez que a ação de descumprimento de preceito fundamental somente veio a ser regulamentada pela Lei n. ${ }^{\circ}$ 9.882, de 3 de dezembro de 1999, que veio a possibilitar o controle direto e concentrado desses atos normativos; continuou a adotar a doutrina das normas constitucionais autoaplicáveis ou não autoaplicáveis de Rui Barbosa (1933, p. 488), que adotou entendimento da jurisprudência americana ao comentar a Constituição Republicana de 1891, o que inviabilizou a aplicação e a eficácia direta das normas constitucionais, especialmente dos direitos fundamentais, ao contrário do dispositivo do $\S 1^{\circ}$ do $\operatorname{artigo} 5^{\circ}$ da Constituição brasileira de 1988; entre outros posicionamentos marcados pela interpretação do novo com olhos do velho.

No regime anterior, o STF, no leading case, em 1977, a respeito da antinomia entre a Convenção de Genebra - que prevê uma lei uniforme sobre letras de câmbios - e a aplicabilidade do Decreto-Lei de n. ${ }^{\circ} 427 / 69$, entendeu, em que pese em vigor, no Direito brasileiro, o referido documento internacional, que prevaleceria o instrumento normativo nacional pelo critério cronológico (STF, RE n. $\left.{ }^{\circ} 8.004,1977\right)$.

Após a promulgação da Constituição brasileira de 1988, com as achegas de outros argumentos, tais como a rigidez constitucional e o direito comparado, manteve o entendimento anterior (STF, RE n. $\left.{ }^{\circ} 8.004,1977\right)$ que, ao fim e ao cabo, equiparou tratados de direitos humanos com a disciplina de títulos de crédito. A respeito da vedação, pela Convenção Americana dos Direitos Humanos, da prisão civil, com exceção ao devedor de obrigação alimentícia (artigo $\left.7^{\circ}(7)\right)$ e a sua possibilidade pela Constituição brasileira de 1988 (artigo $5^{\circ}$, LXVII), em julgamento de habeas corpus (STF, HC n. ${ }^{\circ} 72.131,1995$ ), por maioria de votos, entendeu pela denegação da ordem e não aplicação da convenção. Além do precedente anterior sobre a letra de crédito, foi invocado que, quando o constituinte pretende que a internalização dos tratados de direitos humanos tenha a mesma hierarquia da Lei Maior, fá-lo expressamente, como no caso da Constituição da Argentina, em que há enunciado nesse 
sentido. $^{7}$ Do mesmo modo, sobressaiu o argumento a respeito da rigidez constitucional (SARMENTO, 2018, p. 63), na medida em que o Decreto Legislativo necessita de maioria simples para aprovação, nos termos dos artigos 47 e 49 da Constituição brasileira de 1988, o que não é equiparável com a proposta de Emenda à Constituição (além dos limites ao poder constituído, deve observar a aprovação em cada Casa do Congresso Nacional em dois turnos e por três quintos dos votos dos integrantes, nos termos do artigo $60, \S 2^{\circ}$ ).

Uma das incoerências apontadas acerca do posicionamento inicial do STF é com o parâmetro do artigo 98 do Código Tributário Nacional: “Art. 98. Os tratados e as convenções internacionais revogam ou modificam a legislação tributária interna, e serão observados pela que lhes sobrevenha". A incongruência está em que os tratados de direitos humanos teriam hierarquia legal; ao passo que os de matéria tributária ingressariam com status de supralegalidade no ordenamento jurídico nacional. Ademais, mesmo antes do momento da promulgação da Constituição brasileira de 1988, defendia a igual hierarquia dos tratados de direitos humanos ou mesmo a sua supraconstitucionalidade, entendimento restrito a Celso Albuquerque Mello, que invocava aplicação da norma mais favorável:

\footnotetext{
"norma internacional prevalece sobre a norma constitucional, mesmo naquele caso em que uma norma constitucional posterior tente revogar uma norma internacional constitucionalizada. A nossa posição é a que está consagrada na jurisprudência e trata internacional europeu de que se deve aplicar a norma mais benéfica ao ser humano seja ela interna ou internacional". (MELLO, C. A., 2001, p. 25).
}

Com a defesa da hierarquia constitucional dos tratados de direitos humanos foi o posicionamento do "formulador do texto", Antonio Augusto Cançado Trindade (2003, p. 512), secundado por Flávia Piovesan, Ingo Wolfgang Sarlet, André de Carvalho Ramos, entre outros.

Para Flávia Piovesan (2012, p. 53), uma das pioneiras na doutrina nacional a atentar para a relação especial que se estabeleceu entre o Direito interno e o internacional da proteção aos direitos humanos, em apertada síntese de seus argumentos, os tratados de direitos humanos possuem a mesma hierarquia das normas constitucionais em razão de "interpretação sistemática e teleológica do texto, especialmente em face da força expansiva dos valores da dignidade humana e dos direitos fundamentais, como parâmetros axiológicos a orientar a compreensão do fenômeno constitucional”, aliado à máxima efetividade das normas de

\footnotetext{
${ }^{7}$ Por processo de reforma à Constituição, em 1994, na Argentina, determinados tratados e instrumentos de direitos humanos enumerados possuem hierarquia constitucional e somente podem ser denunciados se antecedidos de aprovação pelo Parlamento (TRINDADE, 2003, p. 513).
} 
direitos fundamentais e aplicabilidade imediata, forte no $\S 1^{\circ}$ do artigo $5^{\circ}$ da Constituição brasileira de 1988, além da globalização que propicia a abertura para as normas de direito internacional de direitos humanos (PIOVESAN, 2012, p. 54). A autora justifica sua posição no contexto da Constituição ser voltada e direcionada para a proteção da pessoa humana e leciona que há um sistema misto com dois regimes jurídicos de incorporação dos tratados internacionais: o primeiro com relação aos que versam sobre direitos humanos com hierarquia constitucional e, sendo assim, compondo o bloco de constitucionalidade, e o segundo, quanto aos demais "tratados tradicionais" com hierarquia de lei federal (PIOVESAN, 2012, p. 55). Leciona que os tratados de direitos humanos anteriores ou posteriores à inclusão do $\S 3^{\circ}$ do artigo $5^{\circ}$ da Constituição brasileira de 1988 são normas materialmente constitucionais, independentemente da forma e do quórum de votação, e, caso opte-se pelo procedimento do novel parágrafo, está-se diante de uma norma material e formalmente constitucional (PIOVESAN, 2012, p. 63).

Flávia Piovesan (2012, p. 64) resume as situações possíveis pela internalização de tratados de direitos humanos: a) coincidência com a Constituição; b) complementar e ampliativa as disposições constitucionais; c) conflitantes com o Direito interno. Quanto aos dois primeiros pontos, não há maiores divergências para a autora, embora, para a posição que se adota no presente estudo, irá surgir a problemática quanto à letra " $b$ ”, visto que a ampliação e complementação das normas de direito ao ambiente poderão contrariar o Direito interno, eventualmente. Pertinente à situação de conflito exposto na letra "c", para Flávia Piovesan, a solução deve obedecer a critérios diversos da clássica noção de resolução de antinomias jurídicas que remonta às hipóteses de especialidade se sobrepor à norma geral, mais nova derroga a remota, e a superior supera a norma inferior. Não é essa a melhor solução, conforme Flávia Piovesan (2012, p. 67), pois se deve lançar mão do que já propôs Antonio Augusto Cançado Trindade ${ }^{8}$, uma solução há muito preconizada pelos conflitos existentes entre normas de direitos humanos e normas de direito fundamental, qual seja: a da preferência da norma mais favorável à vítima e do titular do direito (PIOVESAN, 2012, p. 67-68).

Com contribuições diversas, Ingo Wolfgang Sarlet e André de Carvalho Ramos defendem a igual hierarquia dos tratados de direitos humanos com as normas constitucionais, forte na abertura material do catálogo de direitos fundamentais da Constituição brasileira de

\footnotetext{
${ }^{8}$ Para Antonio Augusto Cançado Trindade (2003, p. 542): "primazia é da norma mais favorável às vítimas, que melhor as proteja, seja ela norma de direito internacional ou de direito interno".
} 
1988, mesmo após a nova regra de procedimento prevista pela reforma do Judiciário (Emenda à Constituição de n. ${ }^{\circ}$ 45), embora sob perspectivas díspares.

Ingo Wolfgang Sarlet (2018, p. 121-122) desfere importantes argumentos para defesa da igual hierarquia dos tratados de direitos humanos com a Constituição. Vai além, e entende que a Declaração Universal dos Direitos do Homem e do Cidadão da ONU de $1948^{9}$, embora com formato de resolução, deve ser inclusa por força da abertura do catálogo, mesmo porque influenciou a redação e a cultura de direitos humanos de diversas Constituições, entre as quais, a Constituição brasileira de 1988 e, conquanto a menção seja restrita a tratados pelo dispositivo constitucional, forte na interpretação sistemática das demais passagens do texto, possível sua incorporação (SARLET, 2018, p. 121-122). Colaciona, em apertado resumo, sem esmiuçar os argumentos lançados pelo constitucionalista, forte em uma interpretação sistemática, o princípio da máxima efetividade dos direitos fundamentais; do princípio da aplicabilidade direta, esculpido no $\S 1^{\circ}$ do artigo $5^{\circ}$ da Constituição brasileira de 1988; princípio da norma mais favorável à pessoa, frente a eventuais colisões com outros dispositivos constitucionais (SARLET, 2018, p. 125-128).

Para André de Carvalho Ramos (2016, p. 306), "como o direito brasileiro vê o direito internacional" se expressa por dois fenômenos: pela incorporação dos tratados e pela impregnação das normas internacionais no Direito brasileiro. Ocupa-se, nesse trabalho, somente do primeiro. O citado autor leciona o entendimento de que se deve considerar com igual hierarquia os tratados de direitos humanos, independente do tempo da incorporação e do rito utilizado, e propõe a reforma textual da Constituição para superar o entendimento do STF, que adotou a teoria do duplo estatuto (RAMOS, 2016, p. 321). Com isso, embora defenda a adoção do bloco de constitucionalidade amplo, com base na abertura material para os tratados de direitos humanos, conclui que o entendimento da jurisprudência do STF é compatível com o bloco de constitucionalidade restrito, a considerar os tratados incorporados pela regra que os equivalem, mas não se igualam a Emendas à Constituição (com o mesmo entendimento: SARLET, 2018, p. 133). A impregnação do direito internacional no Direito interno, na medida em que esse diálogo de normas se dá de forma intensa no direito ambiental, em que muito da legislação interna brasileira, assim como a dos demais países, foi e é influenciada

\footnotetext{
${ }^{9}$ Com o entendimento de que a Declaração Universal dos Direitos Humanos possui força vinculante, malgrado não se constituir em um tratado de direito internacional, segundo Fábio Konder Comparato (2017, p. 240).
} 
pelos tratados que versam sobre a matéria, tem sido objeto de diálogo no decorrer deste trabalho.

Com efeito, a evolução jurisprudencial do STF, até o presente momento, consagrou a teoria do duplo estatuto dos tratados de direitos humanos a depender do rito de sua incorporação: supralegal para os que não seguiram a regra do $\S 3^{\circ}$ do $\operatorname{artigo~} 5^{\circ}$ da Constituição brasileira de 1988 e constitucional para os que a ela foram ou forem submetidos. Com isso, segue-se o entendimento da não imposição do procedimento similar ao de emenda, pois, nos termos defendidos por André de Carvalho Ramos, o Presidente da República, ao encaminhar mensagem ao Congresso Nacional com o tratado para internalização no Direito brasileiro, pode requerer quais dos ritos do processo legislativo deva tramitar: via Decreto Legislativo pelo artigo 49, I; ou pelo $\S 3^{\circ}$ do artigo $5^{\circ}$ da Constituição brasileira de 1988. Mesmo assim, o Congresso Nacional pode contrariar a mensagem presidencial, que é o "senhor da oportunidade" no envio do instrumento, e adotar o rito diverso do escolhido no encaminhamento (RAMOS, 2016, p. 323).

A objeção em favor da imperatividade exposta por Ingo Wolfgang Sarlet (2018, p. 133), embora certamente seria dotado de maior legitimidade e força normativa o tratado que assim tramitar e for aprovado pela maioria de três quintos, em dois turnos de cada Casa Legislativa, de que violaria a segurança jurídica do ordenamento interno e perante o direito internacional, não subiste em razão de que o Estado brasileiro obriga-se a ao menos não contrariar o tratado desde a assinatura, sendo o processo de internalização considerado um mero fato perante a ordem internacional, ou seja: independe do rito e da forma, a obrigação internacional sempre será a mesma. Quanto ao Direito interno, antes de aprovado, seja por qual dos ritos for, não ingressa no mundo jurídico e não há que se falar em violação de princípios.

$\mathrm{O}$ entendimento do duplo estatuto dos tratados internacionais tem suas origens em obter dictum do já aposentado Ministro Sepúlveda Pertence, no HC 79.785-RJ, ao expressar sua posição de que os tratados de direitos humanos, internalizados por Decreto Legislativo e promulgados pelo Decreto Presidencial, deveriam ser observados como normas supralegais e infraconstitucionais. Como é de conhecimento e antes referido, o aparte do Ministro, após sua aposentadoria e noutro contexto e feito, foi a base para formar a maioria e consolidar a jurisprudência do STF a respeito do tema. 
Após a reforma constitucional com a inclusão do $\$ 3^{\circ}$ do $\operatorname{artigo} 5^{\circ}$ da Constituição brasileira de 1988 - que se deu muito em razão do posicionamento refratário do $\mathrm{STF}^{10}$-, no RE 466.343, relatado pelo Ministro Gilmar Mendes, o STF firmou a posição a respeito da supralegalidade dos tratados de direitos humanos, indo ao encontro do entendimento anterior do Ministro Sepúlveda Pertence.

A divergência entre a posição adotada pelo STF a respeito da supralegalidade dos que entendem que os tratados de direitos humanos, independentemente do rito internalizado, têm a mesma hierarquia da Constituição brasileira de 1988 (divergências classificadas, por André de Carvalho Ramos, entre bloco de constitucionalidade restrito e amplo, como sublinhado), mesmo com diferentes consequências, sendo que a principal se compõe ou não da parametricidade para questionar a constitucionalidade de um ato normativo, tem como resultado último a invalidade do ato inferior contrário à norma prevista em tratado com a consequente inconvencionalidade.

A polêmica ganhou novos capítulos e contornos com o tema do amianto. Sua exploração econômica tem sido constante na pauta do STF, questionando-se desde a competência dos entes federados para legislar a respeito até os riscos de violações ao direito à saúde dos trabalhadores e ao direito ambiental ecologicamente protegido, ambos com estatura constitucional e fundamental. O objeto precípuo das demandas que tramitaram no STF foi o exame da constitucionalidade da exploração e da regulamentação pelos Estados-Membros, tendo em vista a divisão de competências constitucionais para legislar sobre o ambiente ${ }^{11}$.

\footnotetext{
${ }^{10}$ Nessa direção é a posição de André de Carvalho Ramos (2016, p. 316), que atribui ao movimento de direitos humanos com a proposta de Emenda à Constituição para inclusão do $\S 3^{\circ}$, do artigo $5^{\circ}$, da Constituição brasileira de 1988, embora tenha sido vista, num primeiro momento, com ceticismo pela doutrina, como por Antonio Augusto Cançado Trindade.

${ }^{11}$ Em um primeiro momento, a Corte posicionou-se acerca da inconstitucionalidade formal dos entes federados regulamentarem a exploração do amianto por excederem a margem de competência concorrente, nos termos da repartição de competência legislativa na Constituição brasileira de 1988, mormente do artigo 24, V, VI e XII, que preveem, respectivamente, o consumo, a proteção do meio ambiente e proteção e defesa da saúde. Nesse sentido é a ADI 2.396/MS proposta pelo Governador de Goiás, relatora Ministra Ellen Gracie, quando foi apreciado o mérito da ação e julgada parcialmente procedente para declarar a inconstitucionalidade de dispositivos de Lei do Estado do Mato Grosso do Sul, que vedou a comercialização e a estocagem de produtos à base de amianto. Constou expressamente no voto da Ministra Relatora que "não cabe a esta corte dar a última palavra a respeito das propriedades técnicos-científicas do elemento em questão e dos riscos de sua utilização para a saúde da população. Os estudos nessa seara prosseguem e suas conclusões deverão nortear as ações das autoridades sanitárias" (STF, ADI 2.396, 2003). O STF, em 04/06/2008, alterou em parte seu entendimento, pois negou referendo à decisão liminar anteriormente proferida pelo Ministro Marco Aurélio em exame da medida cautelar da ADI 3.937/SP (STF, ADI-MC 3.937-7/SP, 2008), ajuizada pela Confederação Nacional dos Trabalhadores na Indústria contra lei do Estado de São Paulo, que proibia o uso do amianto de qualquer espécie. A alteração de jurisprudência não foi, contudo, quanto à possibilidade ou não de exploração do amianto, e sim quanto à possibilidade do estado-membro legislar sobre a matéria, alargando-se, com isso, o entendimento a
} 
Para o presente estudo, o mais importante é que, pela primeira vez, o STF se pronunciou e declarou a supralegalidade ou a hierarquia constitucional de tratados sobre o ambiente e sobre o direito à saúde.

Na primeira ação direta de inconstitucionalidade julgada procedente no STF (ADI 4,066, 2017), que questionou a Lei Federal n. ${ }^{\circ}$ 9.055/1995 (artigo $2^{\circ}$, caput, e parágrafo único), que regulamenta a exploração do amianto, foi alcançada maioria de cinco Ministros pela procedência e quatro pela improcedência e, com isso, não se fez a pronúncia de inconstitucionalidade por não ter sido obtido o quórum necessário de no mínimo seis votos (artigo 97 da Constituição brasileira de 1988). Nesse julgamento, a Ministra relatora Rosa Weber votou expressamente pela hierarquia supralegal das Convenções 139 e 162 da Organização Internacional do Trabalho (promulgadas, respectivamente, pelo Decreto Presidencial n. ${ }^{\circ} 3.197$, de 5 de outubro de 199, e de n. ${ }^{\circ}$ 126, de 22 de maio de 1991), que já tinham sido referidas em obter dictum pelo Ministro Carlos Ayres Brito, e da Convenção da Basileia sobre controle de movimentos transfronteiriços de resíduos perigosos e seu depósito (promulgada pelo Decreto Presidencial de ${ }^{\circ}{ }^{\circ} 875$, de 19 de julho de 1993) e, embora sem a mesma clareza, também, referiu-se à Convenção de Roterdã sobre o procedimento de consentimento prévio informado para o comércio internacional de certas substâncias químicas e agrotóxicos perigosos (promulgada pelo Decreto Presidencial de ${ }^{\circ} .^{\circ} 5.360$, de 31 de janeiro de 2005), com um ponto específico do voto referindo-se ao entendimento da Corte no caso antes citado sobre a Convenção Americana e a impossibilidade de prisão por dívida. O Ministro Luiz Fux, apesar de vencido no mérito, por não acolher a tese da inconstitucionalidade do dispositivo questionado, mencionou e considerou que Convenções da OIT possuem status supralegal, sem referir as outras citadas. Ao passo que os Ministros Luiz Edson Fachin e Celso de Mello reiteraram o posicionamento acerca da hierarquia constitucional dos tratados de direitos humanos, forte na abertura material do catálogo de direitos fundamentais. Os demais Ministros, quer divergindo, quer acompanhando a relatora, nada mencionaram a respeito desse ponto com relação aos instrumentos internacionais referidos, nesse específico julgamento.

Em vista de não ter sido alcançado o quórum para pronúncia da inconstitucionalidade, o tema do amianto retornou à pauta do STF, agora, pela ação direta de inconstitucionalidade

respeito da divisão de competências constitucionais referente ao ambiente. No julgamento de mérito da ADI 3.937/SP também se declarou a inconstitucionalidade incidental da legislação federal que permitia a exploração de amianto. 
contra legislação estadual do Rio de Janeiro, que proibia qualquer atividade, fosse de produção ou de comércio, que envolvesse amianto no referido estado-membro (STF, ADI 3470, 2017), também relatada pela Ministra Rosa Weber.

Como já mencionado, o Ministro Carlos Ayres Brito, em obter dictum, em ação que também questionava o amianto, que foi julgada em conjunto com a ação ora comentada (STF, ADI 3470, 2017), entendeu que as referidas Convenções da OIT (139 e 162) teriam status de supralegalidade, em brevíssima síntese, em razão de que o artigo 59 da Constituição federal de 1988, que disciplina o processo legislativo e estabelece as espécies de atos normativos, não é taxativo e é complementado pelos $\$ \S 2^{\circ}$ e $3^{\circ}$ do artigo $5^{\circ}$, em que os tratados também "são veículos primários de direitos e deveres" (STF, ADI 3357, 2017) e, portanto, retiram da Constituição seu "fundamento mais qualificado de validade" (ADI, 3470, 2017).

A Ministra relatora voltou a considerar os tratados antes referidos como de hierarquia supralegal (STF, ADI 3470, 2017), e a inconstitucionalidade do "amianto" foi pronunciada com o atingimento do quórum, ou seja, é proibida a exploração e qualquer atividade que envolva amianto no Brasil, após a declaração incidental do artigo $2^{\circ}$, caput, e parágrafo único, da Lei Federal n. ${ }^{\circ} 9.055 / 1995$, num claro exemplo de um processo de inconstitucionalização ${ }^{12}$ em razão do avanço da certeza científica acerca dos riscos incontroláveis da exploração do amianto.

Assim, pode-se afirmar que a jurisprudência do STF segue no caminho de considerar os tratados de direitos do ambiente com status de supralegalidade, a não ser que seja adotada a regra de procedimento $\S 3^{\circ}$ do artigo $5^{\circ}$ da Constituição brasileira de 1988 . Conquanto seja sempre uma tarefa complicada de definir a posição do STF, pois a forma de julgamento por onze Ministros cada qual com um voto, cujo acórdão é redigido pelo relator, ao contrário de outras Cortes Constitucionais e Tribunais Internacionais em que o acórdão é um só; e, caso haja divergência, há um voto em separado, como é procedido pela $\mathrm{CIDH}$, tendo em vista a evolução jurisprudencial com julgados anteriores, é possível inferir que o órgão de cúpula da jurisdição constitucional brasileira caminha no sentido de entender que os tratados de direito do ambiente estão abaixo da Constituição e acima da legislação infraconstitucional.

Como referido de passagem, tanto o entendimento que considera de igual hierarquia com a Constituição as normas de direitos humanos internalizadas, independentemente do rito

${ }^{12} \mathrm{O}$ processo de inconstitucionalização foi referido expressamente pelo voto do Ministro Dias Toffoli e consiste em duas possibilidades: alteração textual ou do sentido da parametricidade do controle; mudança fática da realidade subjacente à norma (STF, ADI 3470, 2017). 
adotado, e, portanto, adote o bloco de constitucionalidade amplo, quanto o entendimento do STF a respeito da supralegalidade com o bloco de constitucionalidade restrito, ambos têm como resultado a expulsão do mundo da validade jurídica do ato normativo incompatível, sendo a principal divergência no que tange à extensão das normas paramétricas para fins de controle direto de constitucionalidade. Se o entendimento adotado for do bloco de constitucionalidade amplo, o acesso à jurisdição constitucional terá maiores possibilidades com a inclusão de todos os tratados de direitos humanos; ao contrário, se adotar o bloco de constitucionalidade restrito, os tratados de direitos humanos que servirão como parâmetro serão, tão somente, aqueles que adotarem a regra de procedimento com rito de Emenda à Constituição.

André de Carvalho Ramos (2016, p. 329) expõe que, além da parametricidade ampliada, a adoção do bloco de constitucionalidade traz como consequência que a filtragem constitucional deve levar em consideração a lei fundamental e os tratados internacionais de direitos humanos, assim como todas as normas que compõem o bloco de constitucionalidade, seja ele amplo ou restrito, visto que os atos normativos devem guardar parâmetro e conformidade com o fundamento jurídico superior.

O STF e parte da doutrina, como Daniel Sarmento, colocam uma questão importante de ordem pragmática, que é a falta de segurança jurídica que poderia se observar com a ampliação do texto constitucional para uma infinidade de tratados e convenções internacionais, ou seja: "inflação constitucional sem precedentes, ela geraria absoluta incerteza sobre as normas que efetivamente compõem a nossa Constituição" (SARMENTO, 2018, p. 65). De fato, é uma possibilidade; sem, contudo, o tom catastrófico pinçado pelo constitucionalista carioca.

A ressalva que deve ser feita a esse entendimento é que não são todas as normas dos referidos documentos internacionais que são consideradas de igual hierarquia da Constituição, somente aquelas que estabeleçam direitos humanos ou alguma dimensão específica de um direito fundamental já previsto internamente pela Constituição, com o que já se afasta a possibilidade de inflação. No que diz com o direito ao ambiente, já previsto como fundamental pela Constituição brasileira de 1988, as disposições de tratados incorporados com igual hierarquia constitucional são as estritamente ligadas ao regime jurídico a respeito do âmbito de proteção, da eficácia e efetividade do direito-dever (das dimensões subjetivas e objetivas). 
Seria despiciendo elencar, mas considerando o fato de que o Brasil, quando assina e internaliza um tratado, por via de regra, não está e não se prepara para fazer cumprir os direitos e obrigações assumidas perante a comunidade internacional ou, ainda, quando adotava o "truque de ilusionismo", que, conforme exposto por André de Carvalho Ramos (2016, p. 353), consistia na aplicação das normas internacionais sem dialogar e citar o entendimento dos Tribunais internacionais a respeito do mesmo tema e, com isso, "criar" uma Convenção Americana de Direitos Humanos brasileira, o instrumento internacional importa em obrigações para os Estados de possibilitar eficácia jurídica e efetividade social, independentemente de seu alcance material e espacial.

Para Nadia de Araújo e Inês da Matta Andreiuolo:

\begin{abstract}
"todos os tratados de direitos humanos, qualquer que seja seu alcance material e espacial, comportam para o Estado três obrigações básicas: (i) respeitar os direitos protegidos; (ii) garantir o gozo e o pleno exercício dos direitos protegidos às pessoas que se encontrem sob sua jurisdição; (iii) adotar as medidas necessárias para fazer efetivos os direitos protegidos". (ARAÚJO, ANDREIUOLO, 1999, p. 72).
\end{abstract}

As expressões eficácia jurídica, que é a condição de possibilidade de as normas gerarem efeitos, ou seja, o Estado instrumentalizar a aplicação das disciplinas dos tratados; e efetividade social, que é dar concretude ao programa normativo do tratado, resumem, em duas expressões, o parágrafo das autoras. O Estado brasileiro está, portanto, vinculado aos tratados e instrumentos internacionais que assina, ratifica e internaliza, o que, no caso de algum descumprimento, pode gerar consequências e a responsabilização internacional. A sujeição dá-se tanto ao sistema universal de proteção dos direitos humanos quanto ao sistema regional americano.

O STF tem manifestado, por vezes, sinais contraditórios a respeito do diálogo entre as Cortes e entre as fontes. Se, por um lado, no julgamento da constitucionalidade da Lei de Anistia, sequer foram mencionados os julgados da $\mathrm{CIDH}^{13}$; por outro lado, o diálogo se efetivou no julgamento da prisão por dívida antes comentada, que alterou a sua jurisprudência

\footnotetext{
${ }^{13}$ O STF considerou a Lei de Anistia recepcionada pela Constituição brasileira de 1988, nos termos da decisão da ADPF n. ${ }^{\circ} 153$. A crítica maior não se dá pelo fato de que, logo após esse julgamento, a CIDH, no caso Gomes Lund vs. Brasil, considerou que a Lei de Anistia brasileira era incompatível com a Convenção Americana dos Direitos Humanos, mas sim em razão de que já havia julgamentos similares do órgão jurisdicional do sistema regional americano de proteção dos direitos humanos, e o STF sequer fez menção. Nesse sentido, para Daniel Sarmento (2018, p. 71): "Não é o caso de discutir aqui o acerto ou desacerto da decisão do STF, sob o prisma substantivo. Todavia, não há como não lamentar o absoluto descaso de nossa Suprema Corte em face da jurisprudência da CIDH. O relator e a maior parte dos ministros não fizeram nenhuma referência à jurisprudência internacional, como se ela fosse irrelevante para o deslinde da questão" (grifo no original).
} 
anterior, e no acórdão a respeito da obrigatoriedade do diploma de jornalista para o exercício da profissão propôs e levou em consideração, especialmente no voto do Ministro Gilmar Mendes, a decisão Consultiva n. ${ }^{\circ} 5$ do órgão jurisdicional do sistema regional de proteção dos direitos humanos (STF, RE n. ${ }^{\circ}$ 511.961, 2009). O julgamento da inconstitucionalidade do amianto, como já referido, evidencia votos que trazem entendimentos em que se deve considerar, nas decisões nacionais, os tratados de direitos do ambiente, e que estes ingressam como supralegais para o entendimento firmado pelo STF.

\section{Conclusão}

Mesmo sem a possibilidade de aprofundar o tema das relações entre os países e o direito internacional por meio das decisões judiciais e as propostas dos autores mencionados, em razão dos estreitos limites do presente artigo, quanto a problemática proposta, considerase que o direito-dever fundamental e humano do ambiente compõe o bloco de constitucionalidade (amplo) brasileiro e, portanto, nem fica restrito ao artigo 225, nem ao ambientalismo que se observou em todo o documento da Constituição brasileira de 1988; abrange os tratados de direitos humanos (do ambiente) internalizados, independentemente do rito adotado.

O entendimento a respeito da fundamentalidade constitucional e do bloco de constitucionalidade do direito-dever fundamental e humano ao ambiente redunda não somente na localização hierárquica no topo do ordenamento jurídico brasileiro, mas estabelece, a partir dessa posição, consequências e regime jurídico diverso dos demais direitos positivados, dentre os quais está a "mais-valia" advinda com a dimensão objetiva dos direitos fundamentais e a posição de outras funções atreladas à dimensão subjetiva.

De outra banda, a posição adotada pela maioria do STF que tende a se consolidar de considerar o status de supralegalidade dos tratados internalizados sem que se tenha observado o rito similar aos das Emendas à Constituição tem, por consequência, como ressaltado anteriormente, o afastamento do dispositivo inferior contrário do mundo da validade do ordenamento jurídico nacional.

Embora não tenha sido parte da questão proposta, e renunciou-se a um maior aprofundamento por hora, a problemática persistente é relacionada à definição de quais normas ou dispositivos dos Tratados fazem parte do bloco de constitucionalidade, se todas ou não. A objeção subliminar ao entendimento do STF a respeito da supralegalidade e, 
explicitamente ressaltada por parcela da doutrina, quanto a inflação desmedida de dispositivos legais da Constituição brasileira de 1988 de fato pode acarretar um grave problema de segurança jurídica ao não se saber qual texto deve ser aplicado, se norma constitucional se norma de tratado. Todavia, sem olvidar da importância de se fazer a distinção de que normas possuem hierarquia constitucional e da análise, tratado a tratado, no que diz quanto a esse aspecto, com relação as convenções do ambiente considerá-las como pertencentes ao bloco de constitucionalidade de igual hierarquia constitucional, independentemente do rito adotado para a sua internalização, não só é condizente com evolução constitucional como também acolhe o escorreito entendimento dos dispositivos constitucionais de valoriza da pessoa humana e proteção da natureza.

\section{Referências bibliográficas}

ARAÚJO, Nadia de; ANDREIUOLO, Inês da Matta. "A internalização dos Tratados no Brasil e os Direitos Humanos". In.: BOUCAULT, Carlos Eduardo de Abreu (Org.). Os direitos humanos e o direito internacional. Rio de Janeiro: Renovar, 1999.

BARBOSA, Ruy. Comentários á Constituição Federal Brasileira, (colligidos e ordenados por Homero Pires), Vol. II, São Paulo: Saraiva \& Cia., 1933.

BARROSO, Luís Roberto. Interpretação e Aplicação da Constituição. $7^{a}$ ed., São Paulo: Saraiva, 2009.

CANOTILHO, José Joaquim Gomes. Direito constitucional e teoria da constituição. $7^{\mathrm{a}} \mathrm{Ed}$. $5^{\text {a }}$ reimpressão, Coimbra: Almedina, 2003.

COMPARATO, Fábio Konder. A Afirmação Histórica dos Direitos Humanos. $11^{\mathrm{a}}$ ed. São Paulo: Saraiva, 2017.

Corte Interamericana de Direitos Humanos - CIDH. Opinião Consultiva n⿳ 23, de 15 de novembro de 2017. Disponível em:

<http://www.corteidh.or.cr/docs/opiniones/seriea_23_esp.pdf>. Acesso em: 10/06/2019.

FAVOREOU, Louis. As Cortes Constitucionais. Tradução: Dunia Marinho Silva. São Paulo: Landy Editora, 2004.

KRELL, Andreas Joachim. “Comentário ao artigo 225, caput”. In. CANOTILHO, José Joaquim Gomes; MENDES, Gilmar Ferreira; SARLET, Ingo Wolfgang; STRECK, Lenio Luiz. (Coordenadores científicos) e LEONCY, Léo Ferreira. (Coordenador executivo). Comentários à Constituição do Brasil. São Paulo: Saraiva/Almedina, 2013.

LUÑO, Antonio Enrique Pérez. Derechos Humanos, Estado de Derecho y Constitución. $12^{\mathrm{a}}$ ed. Madrid: Tecnos, 2018. 
MORAIS, Alexandre. Direitos humanos fundamentais. $10^{\mathrm{a}}$ ed. São Paulo: Editora Atlas, 2013.

MELLO, Celso Albuquerque. "O $\S 2^{\circ}$ do Art. $5^{\circ}$ da Constituição Federal”. In.: TORRES, Ricardo Lobo (Org.). Teoria dos Direitos fundamentais. Rio de Janeiro: Renovar, 2001.

NABAIS, José Casalta. O dever fundamental de pagar impostos: contributo para compreensão constitucional do estado fiscal contemporâneo. Coleção teses. Reimpressão. Coimbra: Almedina, 2009.

PIOVESAN, Flávia. Temas de Direitos Humanos. São Paulo: Saraiva, 2012.

RAMOS, André de Carvalho. Teoria Geral dos Direitos Humanos na Ordem Internacional. $6^{\mathrm{a}}$ ed. São Paulo: Saraiva, 2016.

SARLET. Ingo Wolfgang. A eficácia dos direitos fundamentais: uma teoria geral dos direitos fundamentais na perspectiva constitucional. $13^{\mathrm{a}}$ ed. Porto Alegre: Livraria do Advogado, 2018.

SARMENTO, Daniel. "O direito constitucional e o direito internacional: diálogos e tensões". In.: SARMENTO, Daniel. Direitos, Democracia e República: escritos de direito constitucional. Belo Horizonte: Editora Fórum, 2018.

SUPREMO TRIBUNAL FEDERAL. Recurso Extraordinário: RE 8.004 - SE. Relator: Ministro Xavier de Albuquerque. DJ: 29/12/1977. Disponível em: < http://redir.stf.jus.br/paginadorpub/paginador.jsp?docTP=AC\&docID=175365>. Acesso em: 24/05/2019.

SUPREMO TRIBUNAL FEDERAL. Habeas Corpus: HC 72.131-1 - RJ. Relator: Ministro Marco Aurélio. Redator para o acórdão: Ministro Moreira Alves. DJ: 23/11/1995. Disponível em: <http://redir.stf.jus.br/paginadorpub/paginador.jsp?docTP=AC\&docID=73573>. Acesso em: 24/05/2019.

SUPREMO TRIBUNAL FEDERAL. Ação Declaratória de Inconstitucionalidade: ADI 2.396. Relator: Ministra Ellen Grace. DJ 01/08/2003. Disponível em:

$<$ http://redir.stf.jus.br/paginadorpub/paginador.jsp?docTP=AC\&docID=375387> . Acesso em: 06/06/2019.

SUPREMO TRIBUNAL FEDERAL. Ação de Descumprimento de Preceito Fundamental: ADPF 153 - SP. Relator: Ministro Eros Grau. DJ: 29/04/2010. Disponível em: $<$ http://redir.stf.jus.br/paginadorpub/paginador.jsp?docTP=AC\&docID=612960>. Acesso em: 02/09/2019.

SUPREMO TRIBUNAL FEDERAL. Recurso Extraordinário: RE 511.961 - SP. Relator: Ministro Gilmar Mendes. DJ: 17/06/2009. Disponível em:

$<$ http://redir.stf.jus.br/paginadorpub/paginador.jsp?docTP=AC\&docID=605643>. Acesso em: 02/09/2019. 
SUPREMO TRIBUNAL FEDERAL. Ação Direta de Inconstitucionalidade: ADI 4066. Relator: Ministro Rosa Weber. DJ: 07/03/2018. Disponível em: <

http://portal.stf.jus.br/processos/detalhe.asp?incidente=2607856>. Acesso em: 27/11/2019.

STRECK, Lenio Luiz. Jurisdição Constitucional e Hermenêutica: uma nova crítica do direito. Porto Alegre: Livraria do Advogado, 2002.

TRINDADE, Antônio Augusto Cançado. Direitos humanos e meio-ambiente: paralelo dos sistemas de proteção internacional. Porto Alegre: Sérgio Antonio Fabris Editor, 1993.

Tratado de direito internacional dos direitos humanos. Volume 1. $2^{\mathrm{a}}$ ed. Porto Alegre: Sergio Antonio Fabris Editor, 2003. 